\title{
Article \\ The Isolation of Culturable Bacteria in Ixodes ricinus Ticks of a Belgian Peri-Urban Forest Uncovers Opportunistic Bacteria Potentially Important for Public Health
}

\author{
Raphaël Rousseau $^{1, *(\mathbb{D}}$, Sophie O. Vanwambeke ${ }^{1}\left(\mathbb{D}\right.$, Cécile Boland $^{2}\left(\mathbb{D}\right.$ and Marcella Mori ${ }^{2, *}$ \\ 1 Georges Lemaître Centre for Earth and Climate Research, Earth and Life Institute, Université Catholique de \\ Louvain (UCLouvain), Place Pasteur, B-1348 Louvain-la-Neuve, Belgium; sophie.vanwambeke@uclouvain.be \\ 2 Sciensano, Veterinary Bacteriology, Groeselenberg 99, B-1180 Ukkel, Belgium; cecile.boland@sciensano.be \\ * Correspondence: raphael.rousseau@uclouvain.be (R.R.); Marcella.Mori@sciensano.be (M.M.)
}

\section{check for}

updates

Citation: Rousseau, R.;

Vanwambeke, S.O.; Boland, C.; Mori,

M. The Isolation of Culturable

Bacteria in Ixodes ricinus Ticks of a

Belgian Peri-Urban Forest Uncovers

Opportunistic Bacteria Potentially

Important for Public Health. Int. J.

Environ. Res. Public Health 2021, 18,

12134. https://doi.org/10.3390/

ijerph182212134

Academic Editor: Paul B. Tchounwou

Received: 17 September 2021

Accepted: 11 November 2021

Published: 19 November 2021

Publisher's Note: MDPI stays neutral with regard to jurisdictional claims in published maps and institutional affiliations.

Copyright: (C) 2021 by the authors. Licensee MDPI, Basel, Switzerland. This article is an open access article distributed under the terms and conditions of the Creative Commons Attribution (CC BY) license (https:// creativecommons.org/licenses/by/ $4.0 /)$

\begin{abstract}
Most bacteria found in ticks are not pathogenic to humans but coexist as endosymbionts and may have effects on tick fitness and pathogen transmission. In this study, we cultured and isolated 78 bacteria from 954 Ixodes ricinus ticks collected in 7 sites of a Belgian peri-urban forest. Most isolated species were non-pathogenic environmental microorganisms, and were from the Firmicutes (69.23\%), Actinobacteria (17.95\%) and Proteobacteria (3.84\%) phyla. One bacterium isolate was particularly noteworthy, Cedecea davisae, a rare opportunistic bacterium, naturally resistant to various antibiotics. It has never been isolated from ticks before and this isolated strain was resistant to ampicillin, cefoxitin and colistin. Although cultivable bacteria do not represent the complete tick microbiota, the sites presented variable bacterial compositions and diversities. This study is a first attempt to describe the culturable microbiota of ticks collected in Belgium. Further collections and analyses of ticks of different species, from various areas and using other bacterial identification methods would strengthen these results. However, they highlight the importance of ticks as potential sentinel for opportunistic bacteria of public health importance.
\end{abstract}

Keywords: Ixodes ricinus; microbiota; bacterial flora; Cedecea davisae; species diversity

\section{Introduction}

Ticks are important vectors of pathogens affecting humans and animals worldwide [1-3]. These pathogens attract great public heath interest, and many studies tried to estimate the influence of human, environmental, and climatic factors on tick abundance and pathogen prevalence [4-6]. However, tick bacterial composition is not restricted to pathogenic agents. A bigger and richer community of symbiotic, commensal, and parasitic microorganisms coexists in Ixodes ticks, forming a complex microbiota. Pollet et al. defined tick microbiota as "the assemblage of all microorganisms present in and on ticks" [4] (p. 3). Tick microbiota often consists of endosymbionts, engaged in relation with their tick hosts, influencing their fitness, vector capacity and co-infections with pathogenic agents [4,7]. In Wisconsin (United States), male Ixodes scapularis ticks had lower rates of Borrelia burgdorferi infection when they were infected by rickettsial endosymbionts [8]. Considering the potential importance of microbiota in Ixodes ticks and tick-borne pathogens (TBP), as well as the development of new metagenomic approaches, interest has steadily grown in recent years.

Ixodes ricinus is the most widespread tick species in Western Europe and is mainly found in forests, parks, and semi-natural habitats [5]. Its presence and abundance are affected by broad-scale characteristics, e.g., temperature, vegetation type or elevation, and fine-scale characteristics, e.g., undergrowth or the presence of specific hosts [9]. Its microbiota is also highly variable between micro-climates, regions, and habitats [7,9-13]. The relative importance of these factors and their interactions on Ixodes microbiota is not well understood but is currently attracting a growing interest [10]. 
An increasing number of studies on tick microbiota have been published over the past years [14]. Yet, many microorganisms and interactions in tick microbiota are unknown or unidentified $[7,15]$. Bacteria were classically identified with individual strains cultivated in the laboratory. However, they may be unculturable or difficult to culture. Recently, new molecular metagenomic approaches, such as Next Generation Sequencing (NGS), have been developed. This method has been explored for I. ricinus by Carpi et al. [11] and has expanded since (e.g., $[13,16,17])$. The very large number of microorganisms identified by NGS suggests that some have an environmental origin and may be unable to survive and develop in ticks [14]. The composition of tick microbiota consists of microbes vertically transmitted or acquired from local environments [18].

Tick microbiota remains largely unknown but the presence of bacteria of environmental origin may suggest that the local environment influences the presence, abundance, and diversity of bacterial communities in I. ricinus. In this study, Ixodes ticks were collected by dragging in seven sites in a Belgian peri-urban forest throughout the season of tick activity. These sites represent several aspects of the forests in terms of tree covers and undergrowth. We developed a method to isolate and identify culturable bacteria from ticks, and we analyzed their diversity between different sites and different local environments.

\section{Materials and Methods}

\subsection{Study Area}

Ticks were collected at seven locations in the Bois de Lauzelle, a periurban forest of 200 hectares located in the municipalities of Wavre and Ottignies-Louvain-la-Neuve in the Walloon Brabant province of Belgium (Figure 1). The forest is delimited by another forest and a golf facility in the north, and by high-speed roads in the east, south, and west. This private forest is the property and under the management of the neighboring university (UCLouvain) since 1968. The forest has loamy and sandy-loamy soils and is also a Natura 2000 site since 2002 (code BE31006). It has a mean altitude of $103 \mathrm{~m}$ (range: 45-153 m) and its hilly topography is influenced by the Blanc-Ry River.

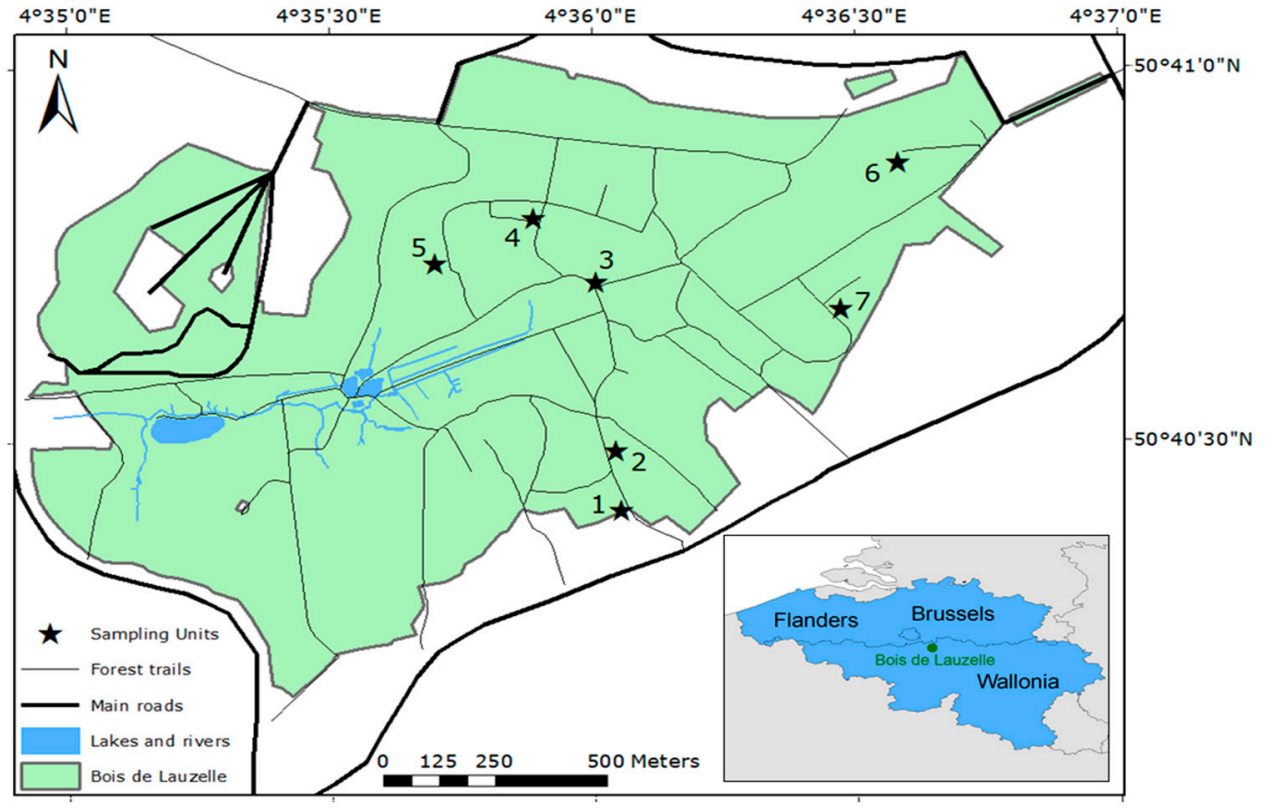

Figure 1. Location of the seven sampling sites in the Bois de Lauzelle.

Seven sites were selected for sampling (Figure 1). In each site, we sampled 1 transect of $10 \mathrm{~m}$ with a $1 \mathrm{~m} \times 1 \mathrm{~m}$ white flannel. The mean distance between two sites is $632 \mathrm{~m}$ (range: 146-1080 m). These sites presented diverse characteristics of the forest (Table 1). The western part of the forest was not accessible. Site 1 was at an entrance of the forest, close to a cub scout's meeting place. The transect was located on a loamy soil covered 
by grass and dead leaves. Site 2 was deeper in the forest, away from the trails on dense undergrowth of brambles and ferns, and dead leaves. Site 3 was at the junction of two trails, close to a bench and an information panel. The underground vegetation was not high or abundant. Site 4 was at the edge of a small clearing, composed by middle-height grass. Site 5 was in an area where trees had recently been cut. The underground vegetation was poor, mainly composed by a layer of moss. Site 6 was close to a barbecue facility, but away from the trails, with a dense undergrowth composed of brambles and ferns, and dead leaves. Site 7 was at the edge between coniferous and deciduous tree stands, away from the trail and with dense undergrowth.

Table 1. Characteristics of the seven sites sampled.

\begin{tabular}{cccccc}
\hline Sites & $\begin{array}{c}\text { Latitude } \\
\text { (Degrees) }\end{array}$ & $\begin{array}{c}\text { Longitude } \\
\text { (Degrees) }\end{array}$ & Forest Type & Soil Vegetation & Soils \\
\hline Site 1 & 4.6021 & 50.6729 & Deciduous & Grass & Loamy \\
Site 2 & 4.6018 & 50.6742 & Deciduous & Brambles & Loamy-Sand \\
Site 3 & 4.6014 & 50.6781 & Deciduous & Grass & Loamy \\
Site 4 & 4.5994 & 50.6794 & Coniferous & Grass & Sandy \\
Site 5 & 4.5963 & 50.6784 & Deciduous & Moss & Sandy \\
Site 6 & 4.6111 & 50.6807 & Deciduous & Brambles & Sandy \\
Site 7 & 4.6089 & 50.6772 & Coniferous & Brambles & Loamy-Sand \\
\hline
\end{tabular}

\subsection{Data Collection and Preparation}

Ticks were sampled in each site every 2 weeks between March and November 2016, by dragging a $1 \mathrm{~m}^{2}$-white flannel 10 times over an area of $10 \mathrm{~m}^{2}$. Ticks were removed and collected after each drag and stored at $-80^{\circ} \mathrm{C}$ until processed for DNA extraction. Larvae were not systematically sampled.

Tick life stage and species were identified using a Leica EZ4 binocular (X35), based on two morphological identification keys [19,20]. After identification, ticks were washed in 3 successive baths for two min each, the first one with $70{ }^{\circ} \mathrm{C}$-alcohol to kill bacteria on the surface and the last two with sterilized water. The water was screened to control sterilization. We made culture from the washing water after the ethanol bath resulting in an absence of bacterial isolation. Then, they were individually smashed in Eppendorfs containing $200 \mu \mathrm{L}$ of Dulbecco's modified Eagle's medium (DMEM) cell culture medium. Vortex mixed homogenate of ticks were grouped in pools of four $(50 \mu \mathrm{L} /$ each, for a total volume of $200 \mu \mathrm{L}$ ) based on the site and season of collection. Larvae were pooled by four, separately from nymphs and adults. A total of $100 \mu \mathrm{L}$ of each pool were placed in culture. Moreover, $50 \mu \mathrm{L}$ in a selective medium based on Agar bacteriological Amersco and antibiotic (Vancomycin, Polymyxin, Trimethoprim and Cephalothin-with the scope of isolation of Francisella tularensis), and $50 \mu \mathrm{L}$ in a non-selective medium. The remaining $100 \mu \mathrm{L}$ were used for DNA extraction.

\subsection{DNA Extraction and High-Resolution Melting Analysis for Ixodes spp. Confirmation}

Initially, $5 \mu \mathrm{L}$ of lysozyme $(10 \mathrm{mg} / \mathrm{mL})$ were added to the $100 \mu \mathrm{L}$ pool medium for DNA extraction. After incubation at $37^{\circ} \mathrm{C}$ for $30 \mathrm{~min}, 200 \mu \mathrm{L}$ of lysis buffer from the $\operatorname{MagMax}^{\mathrm{TM}}$ Isolation Kit and $25 \mu \mathrm{L}$ of proteinase $\mathrm{K}$ were included to continue with an incubation at $56^{\circ} \mathrm{C}$ for $1 \mathrm{~h}$. The homogenate product was then centrifuged at 11,000 rpm for $3 \mathrm{~min}$ and the supernatant processed with the MagMax ${ }^{\mathrm{TM}}$ Isolation Kit (Applied Biosystems; Thermo Fisher Scientific, Inc., Waltham, MA, USA) according to the manufacturer's instructions. Next, $1 / 10$ th of the eluted DNA was used to confirm the tick genus by analysis of polymorphisms in $5 \mathrm{~S}$ and ITS2 genes. This assessment was achieved with the high-resolution melting analysis (HRMA) using a SYBR green based real-time PCR run on a Light cycler ${ }^{\circledR} 480$ Instrument II (Roche Molecular Systems, Inc., Pleasanton, CA, USA). The cycle run consisted of $1 \mathrm{x}$ cycle of $10 \mathrm{~min}$ at $95^{\circ} \mathrm{C}$ followed by 50 cycles of $8 \mathrm{~s}$ at $95^{\circ} \mathrm{C}$, $5 \mathrm{~s}$ at $62{ }^{\circ} \mathrm{C}$ and $5 \mathrm{~s}$ at $72{ }^{\circ} \mathrm{C}$. The last step consisted of a melting curve assessment. The 
results were expressed as melting temperature of the corresponding amplicon. The DNA extracted from the ticks was available for molecular detection of pathogens and will be the subject of further studies. The DNA of isolated bacterial colonies used for whole genome sequencing (WGS) was obtained with the silica-based column method of the DNeasy Blood \& Tissue Kit (Qiagen ${ }^{\circledR}$, Hilden, Germany) following the manufacturer's instructions.

\subsection{Bacterial Identification}

Once the colony was isolated in hard medium, the bacterium was identified by the Bruker MALDI Biotyper IVD MSP Identification Standard Method 1.1. All colonies present on the plate were collected for identification. Only scores above 2 were considered. Alternatively, ribosomal 16S DNA was amplified by standard PCR and sequenced using universal primers 27F and 1492R [21] (list of primes in Supplementary Figure S1). One strain was analyzed by WGS and identified with Kraken (Galaxy Version 2.1.1). A representative diagram of the entire workflow is provided in the Figure S1.

\subsection{Antimicrobial Susceptibility Testing}

The minimum inhibitory concentration (MIC) was determined for 20 antimicrobials with the broth microdilution method using EUVSEC and EUST plates (SensititreTM, Thermo Fisher Scientific, Waltham, MA, USA). Following an 18-24 h incubation period, plates were read with a SensititreTM VizionTM instrument (Thermo Fisher Scientific, Waltham, MA, USA) using Sensivision software (MCS Diagnostics BV, Swalmen, The Netherlands). MICs were interpreted according to EUCAST breakpoints defined for Enterobacterales (http:/ / www.eucast.org/clinical_breakpoints, accessed on 1 January 2021) or epidemiological cut-off values (ECOFF).

\subsection{WGS and In Silico Analysis of Resistance Genes}

WGS was performed on MiSeq platform (Illumina) using protocols defined elsewhere [22]. Briefly, short read sequencing libraries were prepared using a Nextera XT kit (Illumina) and sequenced with a 250-bp paired-end protocol (MiSeq v3 chemistry) according to the manufacturer's instructions. Raw sequencing data of $C$. davisae isolated in this study were submitted to NCBI (https:/ / www.ncbi.nlm.nih.gov/ accessed on 16 September 2021) and are available under the accession number SAMN22562744. For the analysis of genome data, read quality control and trimming were performed with FastQC (Galaxy Version 0.72) and Trimmomatic (Galaxy Version 0.38.0). Genome reference-based assembly was achieved with Bowtie 2 (default settings in Galaxy Version 3.12.0). using the genome of C. davisae DSM 4568 (PRJNA30753) as reference. Derived contigs were analyzed in KEGG Automatic Annotation Server (KAAS, https:/ / www.genome.jp/kegg/kaas/ accessed on 16 September 2021) Ver. 2.1, which provided indication on the antimicrobial resistance determinants. De novo assembly coupled to Resfinder (Galaxy Version 0.2) and KAAS analyses did not retrieve results on resistance determinants, and it was not further used.

\subsection{Bacterial Diversity}

Bacterial diversity between the sites was estimated based on alpha and beta diversity indexes [23,24]. All of the analyses were performed with the vegan package [25] in $\mathrm{R}$ 3.6.3 [26]. Only pools of nymphs and adults were considered for diversity analyses, as larvae were not systematically sampled. Alpha diversity describes the diversity in each site separately and was measured by three indexes. The first index is the abundance, which is the total number of bacteria isolated in ticks by site, regardless of their species. The second, species richness, is the number of different species of bacteria by site, regardless their abundance. The last, species diversity, incorporates both the number of species and their abundance. It was measured here with the Shannon Diversity Index $(\mathrm{H})$ [27]. H is one of the most commonly used diversity indexes in ecology [28]. It characterizes diversity based on the number of species present and the number of organisms per species. The values vary generally between 1 and 4, with low values reflecting low diversity. The number 
of ticks by site and alpha diversity indexes were tested for spatial autocorrelation using Moran's I.

Beta diversity considers differences in diversity between two sites and is represented by the presence or absence of different species between two or more sites [29]. Beta diversity indices were measured here as $\beta_{w}$ from [24]. Since this index may simply increase from an increase in the number of sites sampled, $\beta_{w}$ was calculated from pairwise comparison of sites (Equation (1)).

$$
\beta_{w}=\frac{\frac{(a+b+c)}{(2 a+b+c)}}{2}-1
$$

where $a$ is the number of species shared in the two sites, $b$, the number of unique species in the first site, and $c$, the number of species in the second site. Based on this index, we calculated the Sorensen index of dissimilarity, which varies from zero, indicating that the two sites share all their species, to one when the bacterial communities are totally different.

\section{Results}

\subsection{Description of the Tick Culturable Bacteria}

A total of 954 Ixodes ticks were collected, 86 larvae, 787 nymphs, 37 males and 44 females (Table 2). All of the ticks captured were Ixodidae. One tick was identified as Ixodes ventalloi, 13 as Ixodes frontalis, and the remaining as Ixodes ricinus. A percentage $8.5 \%$ of the ticks were adults. It was relatively constant between the sites, except site 1 with a high percentage of adults (37.9\%). Tick abundance was heterogeneous, ranging from sites with relatively low (sites 1, 3, 5 and 6) to high abundances (sites 2, 4 and 7).

Table 2. Number of ticks collected by life stage, sex, and site.

\begin{tabular}{cccccc}
\hline Site & Larvae & Nymphs & Females & Males & Ticks \\
\hline Site 1 & 0 & 36 & 19 & 3 & 58 \\
Site 2 & 23 & 248 & 10 & 12 & 293 \\
Site 3 & 10 & 71 & 4 & 1 & 86 \\
Site 4 & 38 & 131 & 3 & 6 & 178 \\
Site 5 & 12 & 66 & 2 & 2 & 82 \\
Site 6 & 0 & 60 & 1 & 5 & 66 \\
Site 7 & 3 & 175 & 5 & 8 & 191 \\
Total & 86 & 787 & 44 & 37 & 954 \\
\hline
\end{tabular}

Ticks were grouped in 242 pools. A total of 21 pools were made up exclusively of larvae. After culture, PCR amplification and sequencing, 76 strains were isolated from 63 pools. The list of bacteria isolated from the 242 pools is provided in the Supplementary Materials, (Table S1). Moreover, 26 species were isolated (Figure 2). Three bacteria were not identified neither by the MALDI-TOF MS method nor the ribosomal 16S DNA sequencing. Most strains were environmental bacteria, especially with soil or skin-mucosal origin. Except for the three Proteobacteria, all identified strains were Gram-positive (68/71). Three culturable bacteria were isolated from pools of larvae: Bacillus megaterium, Micrococcus luteus and Staphylococcus hominis. 
Site 1 (15 pools)

Site 2 (73 pools)

Site 3 (23 pools)

Site 4 ( 45 pools)

Site 5 (21 pools)

Site 6 (17 pools)

Site 7 (48 pools)
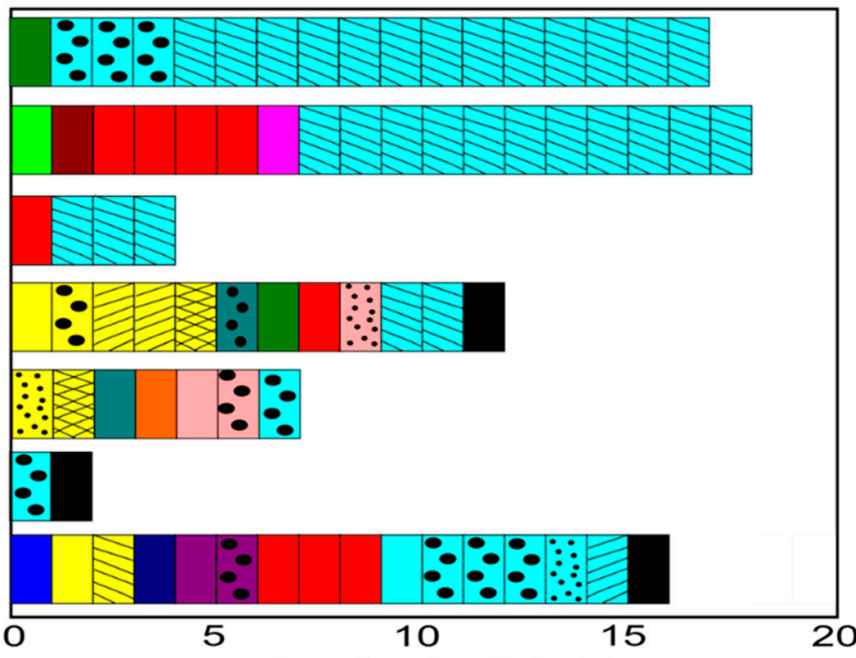

number of pools with isolates

Acinetobacter iwoffii

Bacillus spp.

Brevibacterium casei

Cedecea davisae

Curtobacterium spp.

Micrococcus luteus

Rothia amarae

- Corynebacterium kroppenstedtii

Lysinibacillus fusiformis

Paenibacillus spp.

Staphylococcus spp.
Clostridium spp.

Massilia timonae

Propionobacterium acnes

Bacteria isolated but not identified

When more than one species by genus :

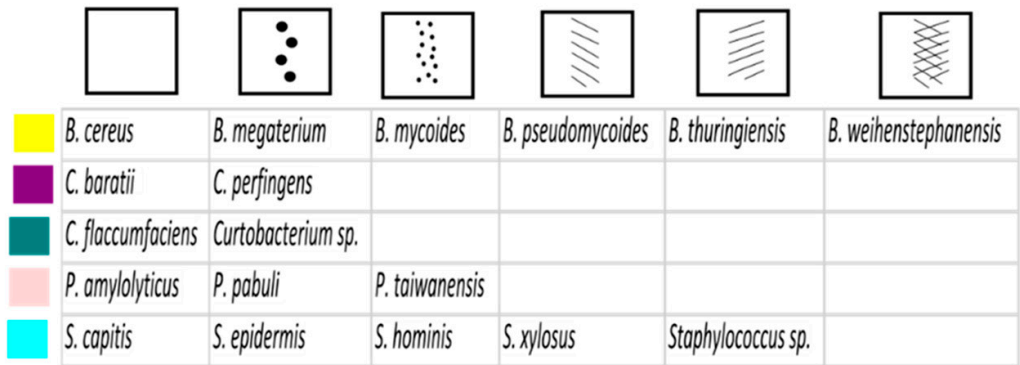

Figure 2. Number of pools with culturable bacterial isolates by site and species. Sometimes more than one species was isolated from the same pool.

Most isolated culturable bacteria were from the Firmicutes phylum (55 isolates from 16 species), mainly from the Staphylococcus (40 isolates) and Bacillus (9 isolates) genera. Staphylococcus xylosus and Staphylococcus epidermidis were isolated 29 and 8 times, respectively (Figure 3). Staphylococcus xylosus was the dominant strain isolated in the most humid environments (sites 1-3). Other Staphylococcus species were S. capitis and S. hominis. One Staphylococcus was not identified. These bacteria are common bacteria of the skin and mucous membranes of humans and animals [30]. Six species of the genus Bacillus were isolated: B. cereus, B. megaterium, B. mycoides, B. pseudomycoides, B. thuringiensis, and $B$. weihenstephanensis. The last Firmicutes species isolated were Clostridium baratii, Clostridium perfingens, Lysinibacillus fusiformis, Paenibacillus amylolyticus, Paenibacillus pabuli and Paenibacillus taiwanensis. 


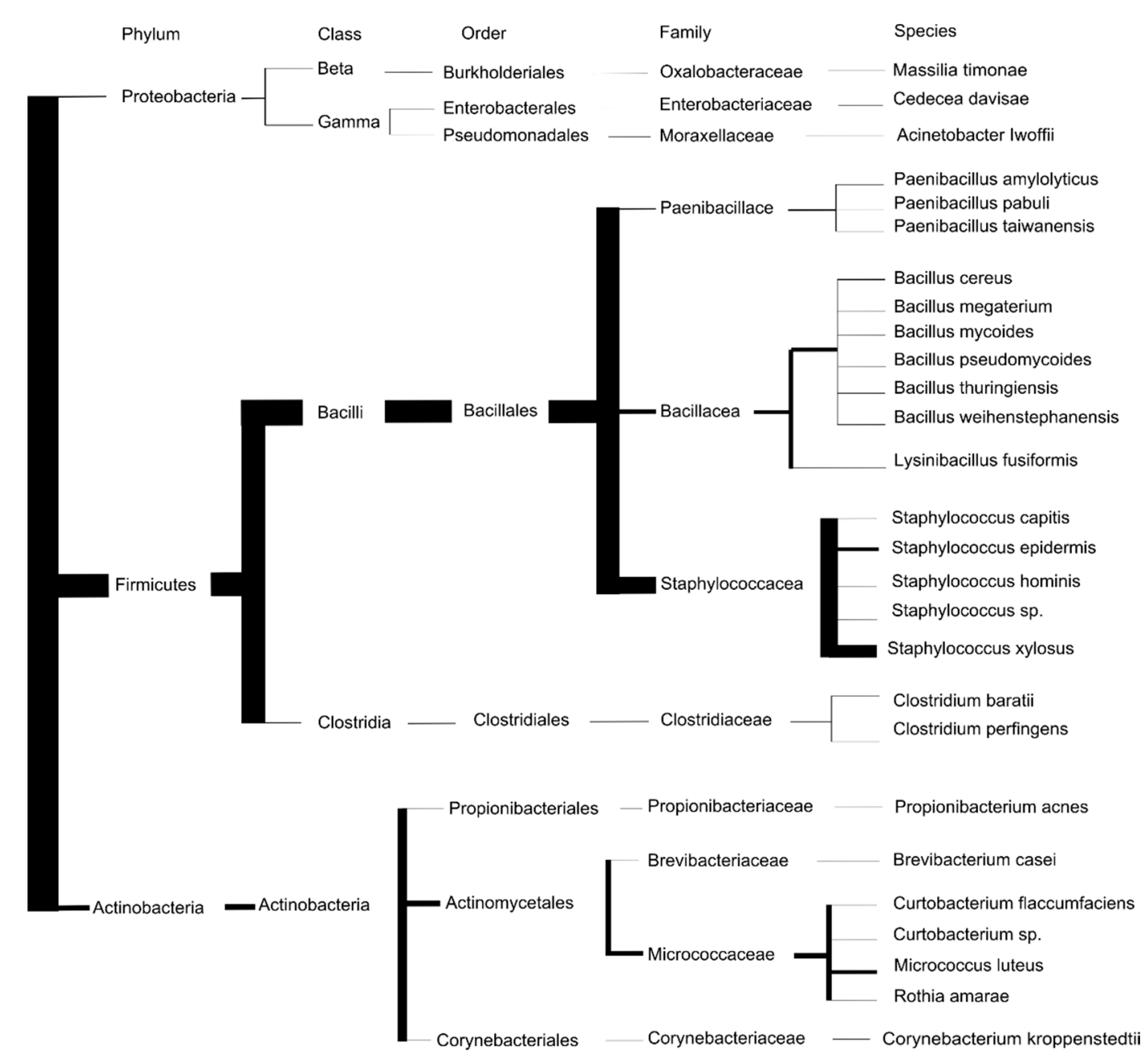

Figure 3. Dendrogram of bacterial species adapted from Bryksin and Matsumura [31] with permission. Branch lengths do not represent evolutionary distance. Branch widths represent the number of bacteria isolated. Only species related to this study are shown.

One-fifth of the culturable bacteria were from Actinobacteria phylum (fifteen isolates from six species). Nine Micrococcus luteus were isolated, from pools from five sites, making it the second most abundant species. Other Actinobacteria were Curtobacterium flaccumfaciens, Rothia amarae, Brevibacterium casei, Corynebacterium kroppenstedtii and Propionibacterium acnes. One Curtobacterium was isolated but not identified.

Three culturable bacteria species were from the Proteobacteria phylum: Acinetobacter lwoffii, Massilia timonae, and Cedecea davisae.

\subsection{Diversity}

We did not include the three unidentified bacteria, Curtobacterium sp., Staphylococcus sp., and the three bacteria isolated from pools of larvae for the diversity analyses (Table 3). A total of 68 bacteria were considered. Sites 1, 2 and 7 presented the highest abundance of bacteria, with, respectively, 18,17 and 13 isolates. Sites 3 and 6 had the lowest, with 4 and 1 strains detected. The abundance of bacterial isolates by site was not correlated with the number of nymphs and adult ticks (Spearman's rho $=0.21, p$-value $=0.66$ ). 
Table 3. Species diversity indices of the bacterial communities in ticks by sites. Pools made up of larvae were excluded. H refers to Shannon Diversity Index, and NA to not available.

\begin{tabular}{ccccc}
\hline Sites & Pools Tested & Species Richness & Abundance & H \\
\hline Site 1 & 15 & 3 & 17 & 0.68 \\
Site 2 & 69 & 5 & 18 & $1 / 11$ \\
Site 3 & 20 & 2 & 4 & 0.56 \\
Site 4 & 35 & 6 & 8 & 1.73 \\
Site 5 & 18 & 7 & 7 & 1.95 \\
Site 6 & 17 & 1 & 1 & 0 \\
Site 7 & 47 & 9 & 13 & 2.06 \\
\hline
\end{tabular}

The richest sites in bacteria species were sites 7,5 and 4 , with, respectively, 9,7 and 6 different species isolated, compared to the less rich sites (6,2, 3 and 1). Sites 7, 5 and 4 were the most diverse $(\mathrm{H}=2.06,1.95$ and 1.73 , respectively), and sites 3,1 and 2 , the least $(\mathrm{H}=0.56,0.68$ and 1.11 , respectively). We could not a compute diversity index for site 6 , as only 1 strain was isolated. Staphylococcus xylosus was abundant in sites with low bacterial diversity (sites 1-3), where they constitute $60-76 \%$ of the strains isolated. In site 1 , S. xylosus was isolated in $86.67 \%$ of the pools (13/15). Except in site 4 , they were absent from sites with high bacterial biodiversity (sites 5 and 7 ).

There was no spatial autocorrelation between sites for the number of adult and nymphal ticks sampled (Moran's I $p$-value $=0.11)$, percentage of adults (Moran's I $p$-value $=0.85$ ), abundance (Moran's I $p$-value $=0.23$ ), species richness (Moran's I $p$-value $=0.46$ ), and Shannon diversity index (Moran's I $p$-value $=0.64$ ).

Beta diversity indices from the Sorensen matrix of dissimilarity between the seven sites were high $($ mean $=0.81$, standard deviation $=0.16)$ indicating that the sites had relatively different communities (Table 4). Sites 2 and 3 were the most similar (index of dissimilarity $=0.43$ ), sharing the 2 most abundant species identified, S. xylosus and M. micrococcus. Site 6 was the less similar site, especially due to the presence of a single identified isolate: S. epidermidis.

Table 4. Sorensen matrix of dissimilarity.

\begin{tabular}{lccccccc}
\hline & Site 1 & Site 2 & Site 3 & Site 4 & Site 5 & Site 6 & Site 7 \\
\hline Site 1 & - & & & & & & \\
Site 2 & 0.75 & - & & & & & \\
Site 3 & 0.60 & 0.43 & - & & & \\
Site 4 & 0.78 & 0.82 & 0.75 & - & & \\
Site 5 & 0.80 & 1 & 1 & 0.85 & - & & \\
Site 6 & 0.50 & 1 & 1 & 1 & 0.75 & - & - \\
Site 7 & 0.83 & 0.86 & 0.82 & 0.87 & 0.88 & 0.80 & - \\
\hline
\end{tabular}

\subsection{Antibiotic Resistance Pattern and Genomic Characteristics of C. davisae}

One bacterium was isolated both in selective and non-selective media, evidencing an intrinsic resistance to various antibiotics, $C$. davisae. Its bacterial identification was confirmed by MALDI-TOF MS, $16 \mathrm{~S}$ rRNA sequencing and WGS. The phenotypic resistance profile of this $C$. davisae strain was characterized through MIC determination for 20 antimicrobials (Table 5). Phenotypic resistance was observed with cefoxitin (MIC of $>16 \mu \mathrm{g} / \mathrm{mL}$ ), ampicillin (MIC of $>64 \mu \mathrm{g} / \mathrm{mL}$ ) and colistin (MIC of $>16 \mu \mathrm{g} / \mathrm{mL}$ ). To gain insight into the molecular features underlying the antimicrobial resistance pattern, WGS data were used to identify orthologs of resistance pathways in KAAS. Within the antimicrobial resistance genes categories, four gene sets were identified: (i) $\beta$-Lactam resistance, (ii) vancomycin resistance, (iii) cationic antimicrobial peptide (CAMP) resistance, including the LPS modification system associated with colistin resistance, and (iv) a miscellanea of genes implicated in multidrug resistance phenotype (complete list given in Supplementary Table S2). In this strain, ampicillin resistance is mediated by genes of the mec family, the bla system 
and the ParR/ParS, CusR/CusS two-component systems. Colistin resistance is associated with lipopolysaccharide (LPS) modification via cationic substitution as the PhoQ/PhoP two-component system is involved. No mor genes (1 to 10) were found excluding the possibility of acquisition of colistin resistance through horizontal gene transfer.

Table 5. MIC $(\mu \mathrm{g} / \mathrm{mL})$ values for the tick-derived C.davisae isolate as defined with the microdilution method Interpretation is based on clinical breakpoints defined by EUCAST (http:/ / www.eucast.org/clinical_breakpoints accessed on 1 January 2021) or ECOFF (indicated by asterisks). Int. stands for interpretation, R. for resistant and S. for sensitive.

\begin{tabular}{|c|c|c|c|c|c|c|c|c|}
\hline \multirow[t]{2}{*}{ Antibiotic Class } & \multirow{2}{*}{$\begin{array}{l}\text { Antibiotic } \\
\text { Abbreviation }\end{array}$} & \multirow[t]{2}{*}{ Antibiotic } & \multicolumn{2}{|c|}{ Cedecea davisae (Tick) } & \multicolumn{2}{|c|}{ Escherichia coli ATCC 25922} & \multicolumn{2}{|c|}{$\begin{array}{l}\text { Enterobacterales (EUCAST } \\
\text { Clinical Breakpoints } 1 \\
\text { January 2021) and ECOFF (*) }\end{array}$} \\
\hline & & & $\mathrm{MIC}(\mu \mathrm{g} / \mathrm{mL})$ & Int. & MIC $(\mu \mathrm{g} / \mathrm{mL})$ & Int. & $\mathbf{S} \leq$ & $\mathbf{R}>$ \\
\hline \multirow{2}{*}{ Aminoglycosides } & GEN & Gentamicin & $\leq 0.5$ & $S$ & $\leq 0.5$ & $S$ & 2 & 2 \\
\hline & STR & Streptomycin & $\leq 4$ & $S^{*}$ & & & & $>16^{*}$ \\
\hline Carbapenem & MERO & Meropenem & 0.12 & $\mathrm{~S}$ & $\leq 0.03$ & $S$ & 2 & 8 \\
\hline \multirow{3}{*}{ Cephalosporins } & FOT & Cefotaxime & $\leq 0.25$ & $S$ & $\leq 0.25$ & $S$ & 1 & 2 \\
\hline & FOX & Cefoxitin & $>16$ & $R^{*}$ & & & $8^{*}$ & $8^{*}$ \\
\hline & TAZ & Ceftazidime & $\leq 0.5$ & S & $\leq 0.5$ & $S$ & 1 & 4 \\
\hline Diterpenes & TIA & Tiamulin & $>4$ & & & & & \\
\hline \multirow{2}{*}{ Fluoroquinolones } & CIP & Ciprofloxacin & $\leq 0.015$ & $S$ & $\leq 0.015$ & $S$ & 0.25 & 0.5 \\
\hline & NAL & Nalidixic Acid & $\leq 4$ & $\mathrm{~S}^{*}$ & $\leq 4$ & $S^{*}$ & & $>8$ \\
\hline $\begin{array}{l}\text { Macrolides, lincosamides } \\
\text { and streptogramins }\end{array}$ & AZI & Azithromycin & 16 & & 4 & & & \\
\hline Penicillins & AMP & Ampicillin & $>64$ & $\mathrm{R}$ & 4 & S & 8 & 8 \\
\hline \multirow{2}{*}{ Tetracyclines } & TET & Tetracycline & $\leq 2$ & $S^{*}$ & $\leq 2$ & $S^{*}$ & & $>8 *$ \\
\hline & TGC & Tigecycline & $\leq 0.25$ & $\mathrm{~S}^{*}$ & $\leq 0.25$ & $S^{*}$ & 1 & $>0.5$ \\
\hline \multirow{7}{*}{ Miscellaneous agent } & $\mathrm{CHL}$ & Chloramphenicol & $\leq 8$ & $S$ & $\leq 8$ & $S$ & 8 & 8 \\
\hline & COL & Colistin & $>16$ & $\mathrm{R}$ & $\leq 1$ & $S$ & 2 & 2 \\
\hline & KAN & Kanamycin & $\leq 4$ & & & & & \\
\hline & MUP & Mupirocin & 256 & & & & & \\
\hline & RIF & Rifampicin & $>0.5$ & & & & & \\
\hline & SMX & Sulfamethoxazole & $>1024$ & & 64 & & & \\
\hline & TMP & Trimethoprim & $\leq 0.25$ & $S$ & 0.5 & $S$ & 4 & 4 \\
\hline
\end{tabular}

* when no clinical breakpoints available, interpretation was based on epidemiological cutoffs (ECOFF) values.

\section{Discussion}

Studying elements of tick microbiota is important because the bacterial flora may specifically influence tick fitness, reproduction, and competence as vectors. These bacteria may also facilitate or compete with tick-borne pathogens [18]. Bacterial phyla distribution and relative abundances found in this study were consistent with previous publications on culturable bacteria. We found the same proportions of the 3 phyla, Firmicutes, Actinobacteria, and Proteobacteria, in the 113 bacteria isolated from the gut of the haematophagous Glossina pallidipes [32]. Six studies analyzed culturable bacteria in Ixodidae ticks, one in Ixodes scapularis in the Unites States [33], one in Ixodes holocyclus in Australia [3], and four in Ixodes ricinus, mostly in central Europe [15,34-36]. (Supplementary Table S3). Most bacterial genera isolated here had already been identified in ticks elsewhere, such as Staphylococcus, Micrococcus, Bacillus, Paenibacillus, Acinetobacter, Propionibacterium. A deeper comparison at the species level was not possible because of the absence of standard method to analyze culturable bacteria, as different culture media target different bacterial communities.

There is, to our knowledge, no scientific information about the composition of Ixodidae microbiota in Belgium, where ticks were mostly screened for known pathogenic agents (e.g., [37]). This study is a first attempt to describe culturable bacterial composition in ticks from Belgium. We discovered a variable diversity of cultivable bacteria genus from ticks collected from the same forest stand. No bacteria species were found at all sites, and the most abundant, S. xylosus, was found in four sites (sites 1-3 and 7). Staphylococcus xylosus is a gram-positive bacterium that is generally not pathogenic, although a few strains are 
related to human infections [38,39]. Another member of the Staphylococcus genus found in this study, S. epidermidis is an opportunistic pathogen widely spread in the environment and in human skins and mucosal surfaces where it can cause nosocomial infections $[30,40]$.

Forest floor structure is important for tick survival and may affect tick microbial composition [9]. For example, soil bacterial communities are very diverse, and even if carbon mineralization rate can explain abundances of specific phyla, the ecological mechanisms explaining this diversity are not fully understood yet [41] The seven sites presented contrasted bacterial diversities in ticks, as indicated by the Sorensen matrix of dissimilarity (Table 5). The more similar sites with the more similar bacterial communities (Site 1 versus Site 3, Site 2 versus Site 3, and Site 1 versus Site 6) were not neighbors. No spatial autocorrelation was found for the microbial diversity. However, the presence of many isolates of S. xylosus in sites 1,2 and 3, relatively close to each other, potentially suggest a localized environmental source. Sites 4,5 and 7 had more abundant and diverse bacterial communities, but no relation with vegetation cover or the type of soils was highlighted, probably due to the small number of sites sampled. Although the number of bacterial strains isolated by site were not correlated with the number of ticks sampled, our indices of biodiversity must be moderated by the number of pools of ticks screened by site.

One of the Proteobacteria isolated from site 2, Cedecea davisae was particularly noteworthy because a common clinical presentation of infection is bacteremia and it is inherently resistant to antibiotics [42,43]. It is a rare opportunistic bacterium, one of the five species in the genus Cedecea, with C. neteri and C. lapagei [44]. Its isolation in ticks needs to be further investigated to see if it can be transmitted through tick bite. Recent molecular techniques revealed an unexpected bacterial diversity in ticks and indicated that the majority of these bacteria are difficult to culture, or even unculturable [18,45]. The culturable bacteria found in Ixodes ticks were typically from four bacterial phyla: Actinobacteria, Bacteroidetes, Firmicutes, and Proteobacteria [46]. Different techniques applied, such as culturing, cloning or species-specific PCR assays, may reveal different taxonomical groups in ticks $[9,16]$. For example, using metagenomic approaches, the dominant bacteria phyla were Proteobacteria, Actinobacteria and Firmicutes [11]. Proteobacteria was the dominant phyla detected in ticks by sequencing with an Illumina MiSeq machine, with 4 other phyla, Actinobacteria, Bacteroidetes, Firmicutes, and Spirochaetes represented by less than $5 \%$ of the total microbiota [47]. The notion of culturable bacteria is also changing through time, as the culturing techniques evolve [48]. Techniques subject to high-throughput sequencing are useful but may overestimate the number of members of the tick microbiota by including many contaminating DNA from environmental sources $[2,9,14]$. Cultures are therefore a useful complementary method for illumina techniques to describe the microbiota composition of ticks.

Most studies focus on bacteria detection from entire ticks [4]. However, the main interest is on the microbiota present in the tick gut because it represents the entry point for tick-borne pathogens [7]. Guizzo et al. [41] found that the microbiota of the tick midgut was less abundant and more diverse than the rich but poorly diverse ovarian microbiota, dominated by Midichloria sp. Carpi et al. [11] also observed variation in the occurrence of bacteria among individual ticks. The present study identified a limited and variable number of bacteria in ticks, that were closely related to those found previously in the tick midgut [41]. Their transmission through tick bites requires further functional studies. Bacteria detected in cultures from ticks may not necessarily be part of the tick microbiota; they might indicate temporal contamination from an environmental source. Some bacteria we identified are also found in plants, soils, or the skin of other animals and could be part of the tick exoskeleton. The detection of culturable bacteria in three larvae pools may reflect contamination. The presence of contamination cannot therefore be excluded but is limited in this study for the following reasons. Tick skin bacteria were probably removed, due to the storage at $-80^{\circ} \mathrm{C}$ between the samplings and the analyzes. A strict surface washing with ethanol and sterilized water was also performed on each tick before DNA extraction. For further studies, Binetruy et al. [49] recently indicated that bleach 
should be used over ethanol for tick washing, as the latter method may impact internal bacterial diversity in metagenomics sequencing-based studies, as DNA can easily stick to tick cuticle. Kmet' and Čaplová [1] identified the same species of Staphylococcus, Bacillus, Micrococcus and Brevibacillus in ethanol sterilized ticks. The bacteria identified here were with distinct homogeneous prints, which is normally excluded in bacteria isolated from outside the ticks.

The spatial and temporal scales are important in studies of tick microbial communities $[4,18]$. Interactions between microorganisms and the environment depend on the scale at which we consider these interactions. The density of specific animals, with variable reservoir competences, is also important to understand variations in tick microbiota at the local scale [50]. Differences in microbial communities between large areas, climatically and environmentally varied is not surprising. However, in this study, ticks were sampled from seven sites, distant of $632 \mathrm{~m}$ on average, in the same forest stand. Wildlife movements are not limited in this forest, which presents contrasted micro-climates in relation to different flora composition and topography. The sites sampled had contrasted culturable bacterial communities.

\section{Conclusions}

It is now clear that TBP are not the only microorganisms present in Ixodes ticks, which harbor larger, and still poorly understood microbiota communities. They are particularly important in the TBP complex system as they may influence tick fitness and behavior and interact with other pathogenic and non-pathogenic agents. Recent identifications of tick microorganisms based on several methods and technologies, such as NGS, identified an increasing number of bacteria. It remains questionable if these bacteria are part of tick microbiota or environmental contaminant, unable to physiologically survive and develop in ticks. Using cultures of ticks from the same forest stand, we found complex and variable bacterial communities.

The culturable bacteria found in this study were variable across the seven sites, but consistent with those found in the literature for Ixodes ticks. Bacteria from the Firmicutes phylum were the most abundant, followed by the Actinobacteria and the Proteobacteria phyla. Most strains were only isolated once or two times, except S. xylosus, S. epidermidis and $M$. luteus. The isolation of a strain of $C$. davisae naturally resistant to antibiotics was surprising as it has never been isolated from ticks before, and the transmission of this bacteria through tick bite needs confirmation from other studies. It may suggest a potential tick-mediated transmission of this opportunistic pathogen. The identified culturable bacteria here did not represent the complete tick microbiota, and some isolates might originate from environmental sources, even if this risk was limited with prior washings. It was the first attempt to describe a part of the tick microbiota in Belgium. The bacteria identified were consistent with the literature, but the results need to be confirmed with ticks from other areas, other species, other cultures, and other bacterial identification methods. This information is crucial to help understanding tick-bacteria interactions and detecting the presence of new bacteria in tick microbiota.

Supplementary Materials: The following are available online at https://www.mdpi.com/article/10.3 390/ijerph182212134/s1, Figure S1. Melting curves derived from analysis of the 5S and ITS2 sequence polymorphisms in Ixodes and Dermacentor spp.by HRMA. Derivative fluorescent emission data recorded during the melting step. Two main profiles were observed with different Tms, the Ixodes spp. group (dark green and brown lines) and the Dermacentor spp. group (green, light blue and fuchsia lines). Primers designed for the analysis: primers on 5S for Ixodes ricinus: FW: gtcgtagccttccgtcagtc, RV: acggcattccctactggat; primers on ITS2 for Dermacentor spp: FW: cggacacctgcagggaaag, RV: cttccgactctctcgcaaac. Table S1. Pools tested for the isolation and identification of cultivable bacteria by site, season, and tick development stage. Table S2. List of resistance genes and of their orthologs present in the tick-derived $C$. davisae genome as defined with the KAAS analysis. Table S3. Previous scientific publications describing culturable bacteria in Ixodes ticks. T. stands for ticks, L. for larvae, N for nymphs, A for adults, M for males and F for females. NA stands for not available. 
Author Contributions: Conceptualization, R.R., M.M. and S.O.V.; methodology, R.R., M.M. and S.O.V.; software, R.R. and M.M.; validation, R.R., M.M. and S.O.V.; formal analysis, R.R. and M.M.; investigation, R.R. and M.M.; resources, M.M. and S.O.V.; data curation, R.R., M.M. and C.B.; writing-original draft preparation, R.R.; writing—review and editing, R.R., M.M., S.O.V. and C.B.; visualization, R.R. and M.M.; supervision, M.M. and S.O.V.; project administration, M.M. and S.O.V.; funding acquisition, no external funding. All authors have read and agreed to the published version of the manuscript.

Funding: This research received no external funding.

Institutional Review Board Statement: Not applicable.

Informed Consent Statement: Not applicable.

Data Availability Statement: The data that support the findings of this study are available on request from the corresponding author.

Acknowledgments: The authors would like to acknowledge Elliott Wolter, who sampled the ticks during his master thesis. The authors also warmly acknowledge Martine Marin, Sébastien Landrain and Nihazi Saiti for their help performing the extractions, identifications, and sequencings under the supervision of Marcella Mori. Finally, the authors acknowledge Alexandru Radu for performing the MALDI analyses and supervising the MIC analyses.

Conflicts of Interest: The authors declare no conflict of interest.

\section{References}

1. Kmet', V.; Čaplová, Z. An update on the Ixodes ricinus microbiome. J. Microbiol. Biotechnol. Food Sci. 2019, 8, 1340-1342. [CrossRef]

2. Lejal, E.; Estrada-Peña, A.; Marsot, M.; Cosson, J.F.; Rué, O.; Mariadassou, M.; Midoux, C.; Vayssier-Taussat, M.; Pollet, T. Taxon appearance from extraction and amplification steps demonstrates the value of multiple controls in tick microbiota analysis. Front. Microbiol. 2020, 11, 1-10. [CrossRef]

3. Murrell, A.; Dobson, S.J.; Yang, X.; Lacey, E.; Barker, S.C. A survey of bacterial diversity in ticks, lice and fleas from Australia. Parasitol. Res. 2003, 89, 326-334. [CrossRef] [PubMed]

4. Pollet, T.; Sprong, H.; Lejal, E.; Krawczyk, A.I.; Moutailler, S.; Cosson, J.F.; Vayssier-Taussat, M.; Estrada-Peña, A. The scale affects our view on the identification and distribution of microbial communities in ticks. Parasites Vectors 2020, 13, 1-13. [CrossRef]

5. Medlock, J.M.; Hansford, K.M.; Bormane, A.; Derdakova, M.; Estrada-Peña, A.; George, J.-C.; Golovljova, I.; Jaenson, T.G.T.; Jensen, J.-K.; Jensen, P.M.; et al. Driving forces for changes in geographical distribution of Ixodes ricinus ticks in Europe. Parasites Vectors 2013, 6, 1-11. [CrossRef] [PubMed]

6. Vanwambeke, S.O.; Van doninck, J.; Artois, J.; Davidson, R.K.; Meyfroidt, P.; Jore, S. Forest classes and tree cover gradient: Tick habitat in encroached areas of southern Norway. Exp. Appl. Acarol. 2016, 68, 375-385. [CrossRef]

7. Bonnet, S.I.; Binetruy, F.; Hernández-Jarguín, A.M.; Duron, O. The tick microbiome: Why non-pathogenic microorganisms matter in tick biology and pathogen transmission. Front. Cell. Infect. Microbiol. 2017, 7, 1-14. [CrossRef]

8. Steiner, F.E.; Pinger, R.R.; Vann, C.N.; Grindle, N.; Civitello, D.; Clay, K.; Fuqua, C. Infection and co-infection rates of Anaplasma phagocytophilum variants, Babesia spp., Borrelia burgdorferi, and the rickettsial endosymbiont in Ixodes scapularis (Acari: Ixodidae) from sites in Indiana, Maine, Pennsylvania, and Wisconsin. J. Med. Entomol. 2008, 45, 289-297. [CrossRef]

9. Van Overbeek, L.; Gassner, F.; Van Der Plas, C.L.; Kastelein, P.; Nunes-Da Rocha, U.; Takken, W. Diversity of Ixodes ricinus tick-associated bacterial communities from different forests. FEMS Microbiol. Ecol. 2008, 66, 72-84. [CrossRef]

10. Aivelo, T.; Norberg, A.; Tschirren, B. Bacterial microbiota composition of Ixodes ricinus ticks: The role of environmental variation, tick characteristics and microbial interactions. PeerJ 2019, 2019, 1-25. [CrossRef]

11. Carpi, G.; Cagnacci, F.; Wittekindt, N.E.; Zhao, F.; Qi, J.; Tomsho, L.P.; Drautz, D.I.; Rizzoli, A.; Schuster, S.C. Metagenomic profile of the bacterial communities associated with Ixodes ricinus ticks. PLOS ONE 2011, 6, 1-11. [CrossRef]

12. Estrada-Peña, A.; Cabezas-Cruz, A.; Pollet, T.; Vayssier-Taussat, M.; Cosson, J.F. High Throughput Sequencing and network analysis disentangle the microbial communities of ticks and hosts within and between ecosystems. Front. Cell. Infect. Microbiol. 2018, 8, 1-12. [CrossRef]

13. Vayssier-Taussat, M.; Moutailler, S.; Michelet, L.; Devillers, E.; Bonnet, S.; Cheval, J.; Hébert, C.; Eloit, M. Next generation sequencing uncovers unexpected bacterial pathogens in ticks in western Europe. PLoS ONE 2013, 8. [CrossRef]

14. Stewart, P.E.; Bloom, M.E. Sharing the ride: Ixodes scapularis symbionts and their interactions. Front. Cell. Infect. Microbiol. 2020, 10, 1-12. [CrossRef]

15. Rudolf, I.; Mendel, J.; Šikutová, S.; Švec, P.; Masaříková, J.; Nováková, D.; Buňková, L.; Sedlácek, I.; Hubáleks, Z. 16S rRNA gene-based identification of cultured bacterial flora from host-seeking Ixodes ricinus, Dermacentor reticulatus and Haemaphysalis concinna ticks, vectors of vertebrate pathogens. Folia Microbiol. 2009, 54, 419-428. [CrossRef] [PubMed] 
16. Barbosa, A.D.; Gofton, A.W.; Paparini, A.; Codello, A.; Greay, T.; Gillett, A.; Warren, K.; Irwin, P.; Ryan, U. Increased genetic diversity and prevalence of co-infection with Trypanosoma spp. in koalas (Phascolarctos cinereus) and their ticks identified using next-generation sequencing (NGS). PLoS ONE 2017, 12, 1-20. [CrossRef] [PubMed]

17. Vayssier-Taussat, M.; Kazimirova, M.; Hubalek, Z.; Hornok, S.; Farkas, R.; Cosson, J.-F.; Bonnet, S.; Vourch, G.; Gasqui, P.; Mihalca, A.D.; et al. Emerging horizons for tick-borne pathogens: From the "one pathogen-one disease" vision to the pathobiome paradigm. Future Microbiol. 2015, 10, 2033-2043. [CrossRef]

18. Bonnet, S.I.; Pollet, T. Update on the intricate tango between tick microbiomes and tick-borne pathogens. Parasite Immunol. 2021, 43, 1-12. [CrossRef] [PubMed]

19. Heylen, D.; De Coninck, E.; Jansen, F.; Madder, M. Differential diagnosis of three common Ixodes spp. ticks infesting songbirds of Western Europe: Ixodes arboricola, I. frontalis and I. ricinus. Ticks Tick-Borne Dis. 2014, 5, 693-700. [CrossRef] [PubMed]

20. Hillyard, P.D. Ticks of North-West Europe; The Natura: London, UK, 1996.

21. Frank, J.A.; Reich, C.I.; Sharma, S.; Weisbaum, J.S.; Wilson, B.A.; Olsen, G.J. Critical evaluation of two primers commonly used for amplification of bacterial 16S rRNA genes. Appl. Environ. Microbiol. 2008, 74, 2461-2470. [CrossRef]

22. Tomaiuolo, S.; Boarbi, S.; Fancello, T.; Michel, P.; Desqueper, D.; Grégoire, F.; Callens, J.; Fretin, D.; Devriendt, B.; Cox, E.; et al. Phylogeography of Human and Animal Coxiella burnetii Strains: Genetic Fingerprinting of Q Fever in Belgium. Front. Cell. Infect. Microbiol. 2021, 10, 1-15. [CrossRef]

23. Leung, E.T.; Noronha, R.; Mirza, A.; Shenwai, R.; Mpatziakas, A. Shinydiversity-Understanding alpha and beta diversity through interactive visualizations. F1000Research 2018, 7, 1-12. [CrossRef]

24. Whittaker, R.H. Vegetation of the Siskiyou Mountains, Oregon and California. Ecol. Monogr. 1960, 30, 279-338. [CrossRef]

25. Oksanen, J.; Blanchet, F.G.; Friendly, M.; Kindt, R.; Legendre, P.; McGlinn, D.; Minchin, P.R.; O’Hara, R.B.; Simpson, G.L.; Solymos, P.; et al. Vegan: Community Ecology Package; 2020. Available online: https: / /CRAN.R-project.org/package=vegan (accessed on 10 November 2021).

26. R Core Team. R: A Language and Environment for Statistical Computing; R Foundation for Statistical Computing: Vienna, Austria, 2020; Available online: http:/ / www.R-project.org/ (accessed on 10 November 2021).

27. Shannon, C.E. A mathematical theory of communication. Bell Syst. Tech. J. 1948, 27, 379-423. [CrossRef]

28. Hill, M.O. Diversity and Evenness: A Unifying Notation and Its Consequences. Ecology 1973, 54, 427-432. [CrossRef]

29. Koleff, P.; Gaston, K.J.; Lennon, J.J. Measuring beta diversity for presence-absence data. J. Anim. Ecol. 2003, 72, 367-382. [CrossRef]

30. Otto, M. Staphylococcus epidermidis-The "accidental" pathogen. Nat. Rev. Microbiol. 2009, 7, 555-567. [CrossRef]

31. Bryksin, A.V.; Matsumura, I. Rational design of a plasmid origin that replicates efficiently in both gram-positive and gram-negative bacteria. PLoS ONE 2010, 5, 1-9. [CrossRef]

32. Malele, I.; Nyingilili, H.; Lyaruu, E.; Tauzin, M.; Bernard Ollivier, B.; Cayol, J.L.; Fardeau, M.L.; Geiger, A. Bacterial diversity obtained by culturable approaches in the gut of Glossina pallidipes population from a non sleeping sickness focus in Tanzania: Preliminary results 06 Biological Sciences 0605 Microbiology. BMC Microbiol. 2018, 18, 107-116. [CrossRef]

33. Martin, P.A.W.; Schmidtmann, E.T. Isolation of aerobic microbes from Ixodes scapularis (Acari: Ixodidae), the vector of Lyme disease in the Eastern United States. J. Econ. Entomol. 1998, 91, 864-868. [CrossRef]

34. Egyed, L.; Makrai, L. Cultivable internal bacterial flora of ticks isolated in Hungary. Exp. Appl. Acarol. 2014, 63, 107-122. [CrossRef]

35. Okła, H.; Sosnowska, M.; Jasik, K.P.; Słodki, J.; Wojtyczka, R.D.; Wojtyczka, R.D. Nonspecific bacterial flora isolated from the body surface and inside Ixodes ricinus ticks. Polish J. Microbiol. 2012, 61, 205-209. [CrossRef]

36. Stojek, N.M.; Dutkiewicz, J. Studies on the occurrence of gram-negative bacteria in ticks: Ixodes ricinus as a potential vector of Pasteurella. Ann. Agric. Environ. Med. 2004, 11, 319-322. [PubMed]

37. Lernout, T.; De Regge, N.; Tersago, K.; Fonville, M.; Suin, V.; Sprong, H. Prevalence of pathogens in ticks collected from humans through citizen science in Belgium. Parasites Vectors 2019, 12, 1-11. [CrossRef] [PubMed]

38. Dordet-Frisoni, E.; Dorchies, G.; De Araujo, C.; Talon, R.; Leroy, S. Genomic diversity in Staphylococcus xylosus. Appl. Environ. Microbiol. 2007, 73, 7199-7209. [CrossRef]

39. Kloos, W.E.; Zimmerman, R.J.; Smith, R.F. Preliminary studies on the characterization and distribution of Staphylococcus and Micrococcus species on animal skin. Appl. Environ. Microbiol. 1976, 31, 53-59. [CrossRef] [PubMed]

40. Namvar, A.E.; Bastarahang, S.; Abbasi, N.; Ghehi, G.S.; Farhadbakhtiarian, S.; Arezi, P.; Hosseini, M.; Baravati, S.Z.; Jokar, Z.; Chermahin, S.G.; et al. Clinical characteristics of Staphylococcus epidermidis: A systematic review. GMS Hyg. Infect. Control 2014, 9 , 1-10. [CrossRef]

41. Guizzo, M.G.; Neupane, S.; Kucera, M.; Perner, J.; Frantová, H.; da Silva Vaz, I.; de Oliveira, P.L.; Kopacek, P.; Zurek, L. Poor unstable midgut microbiome of hard ticks contrasts with abundant and stable monospecific microbiome in ovaries. Front. Cell. Infect. Microbiol. 2020, 10, 1-10. [CrossRef] [PubMed]

42. Abate, G.; Qureshi, S.; Mazumder, S.A. Cedecea davisae bacteremia in a neutropenic patient with acute myeloid leukemia. J. Infect. 2011, 63, 83-85. [CrossRef]

43. Thompson, D.K.; Sharkady, S.M. Expanding spectrum of opportunistic Cedecea infections: Current clinical status and multidrug resistance. Int. J. Infect. Dis. 2020, 100, 461-469. [CrossRef]

44. Dalamaga, M.; Karmaniolas, K.; Arsenis, G.; Pantelaki, M.; Daskalopoulou, K.; Papadavid, E.; Migdalis, I. Cedecea lapagei bacteremia following cement-related chemical burn injury. Burns 2008, 34, 1205-1207. [CrossRef] 
45. Martiny, A.C. High proportions of bacteria are culturable across major biomes. ISME J. 2019, 13, 2125-2128. [CrossRef] [PubMed]

46. Tanaka, Y.; Matsuzawa, H.; Tamaki, H.; Tagawa, M.; Toyama, T.; Kamagata, Y.; Mori, K. Isolation of novel bacteria including rarely cultivated phyla, Acidobacteria and Verrucomicrobia, from the roots of emergent plants by simple culturing method. Microbes Environ. 2017, 32, 288-292. [CrossRef]

47. van Treuren, W.; Ponnusamy, L.; Brinkerhoff, R.J.; Gonzalez, A.; Parobek, C.M.; Juliano, J.J.; Andreadis, T.G.; Falco, R.C.; Ziegler, L.B.; Hathaway, N.; et al. Variation in the microbiota of Ixodes ticks with regard to geography, species, and sex. Appl. Environ. Microbiol. 2015, 81, 6200-6209. [CrossRef] [PubMed]

48. Molina-Menor, E.; Gimeno-Valero, H.; Pascual, J.; Peretó, J.; Porcar, M. High culturable bacterial diversity from a European desert: The Tabernas desert. Front. Microbiol. 2021, 11, 1-15. [CrossRef] [PubMed]

49. Binetruy, F.; Dupraz, M.; Buysse, M.; Duron, O. Surface sterilization methods impact measures of internal microbial diversity in ticks. Parasites Vectors 2019, 12,1-10. [CrossRef]

50. Randolph, S.E. The shifting landscape of tick-borne zoonoses: Tick-borne encephalitis and Lyme borreliosis in Europe. Philos. Trans. R. Soc. London. Ser. B Biol. Sci. 2001, 356, 1045-1056. [CrossRef] 